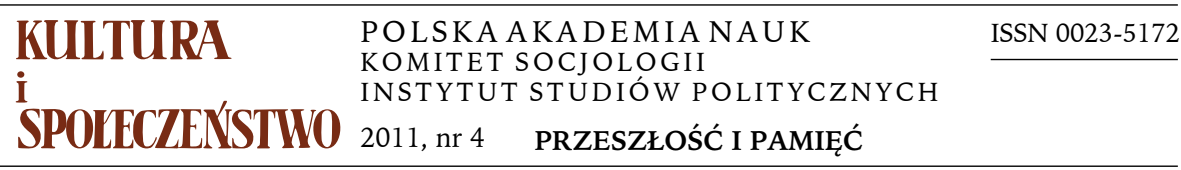

CHRISTOPH HAMANN

Landesinstitut für Schule und Medien, Berlin-Brandenburg $w$ Poczdamie

\title{
INDEKS, IKONA I SYMBOL O STOSUNKU FOTOGRAFII, HISTORII (CZASU) I PAMIĘCI
}

W swej ostatniej publikacji z roku 1980, eseju Światto obrazu. Uwagi o fotografii, francuski myśliciel Roland Barthes formułuje interesujące stwierdzenie: „Ten sam wiek - pisze - wynalazł Historię i Fotografię” (Barthes 2008, s. 166). Ta zbieżność w czasie inspiruje do porównania cech wspólnych i różnic między nauką $z$ jednej strony a medium $z$ drugiej. Na gruncie historii nauki porównanie to można by budować na równoczesnym działaniu prekursorów fotografii i historiografii. Za duchowych ojców fotografii uważa się Nicephore'a Niepce (1765-1833), który w 1826 roku wykonal pierwsze (przypuszczalnie) na stałe utrwalone zdjęcie, oraz Louisa Jacques'a Mande Daguerre (1787-1851), którego dagerotypia została po raz pierwszy zademonstrowana publicznie w 1839 roku. Leopold von Ranke (1795-1886), jeden z ojców założycieli nowoczesnych nauk historycznych w Niemczech, zaczął publikować w latach dwudziestych XIX wieku. W 1839 roku ukazał się pierwszy tom jego Deutsche Geschichte im Zeitalter der Reformation [Historia Niemiec w okresie reformacji].

Stwierdzenie, że ojcowie założyciele działali w tym samym czasie, jest wprawdzie interesujące, ale oczywiście nie wystarcza do wyraźnego nakreślenia istoty powiązań między nauką i medium. Należy więc zapytać: Co je łączy ponadto? A co dzieli? Co jest ich specyfiką? Jakie zmiany wynikają z digitalizacji? Dwie początkowe części tego artykułu zaczynają się od analizy specyfiki zdjęcia fotograficznego, które świadczy wprawdzie o przeszłości, jednak nie opowiada historii. Później zostają szkicowo przedstawione możliwości tego medium, które nie tylko reprezentuje przeszłość, lecz w teraźniejszości i przyszłości może stanowić impuls pobudzający do działania. Kolejne trzy części pokazują — w nawiązaniu do klasyfikacji znaków semiotyka Charlesa Sandersa

Adres do korespondencji: chriherr@yahoo.de 
Peirce'a (1839-1914) — na czym polega ważna dla nauk historycznych funkcja fotografii jako indeksu, ikony i symbolu. Ten podział pomaga zarazem zrozumieć sposób posługiwania się zbiorowym zasobem zdjęć oraz, dokładniej, określić status zdjęć cyfrowych jako źródła. Na koniec zostaje podjęta próba pokazania perspektyw analizy visual history, wyznaczających rolę posługiwania się obrazami przy formowaniu i zmienianiu wspólnot pamięci w epoce globalizacji i dywersyfikacji.

\section{FOTOGRAFIA A HISTORIA}

Podobieństwa nauki i medium pozwala uchwycić na przykład porównawczy opis ich funkcji. Funkcja fotografii jako medium pamięci historycznej, według zajmującej się historią fotografii Cornelii Brink, może być uznana „wręcz za topos fototeoretyczny i fotohistoryczny" (Brink 1998, s. 17). Historyk sztuki Horst Bredekamp wychodzi z założenia, że „kultura pamięci w dużym stopniu opiera się obecnie na prywatnych i publicznych zbiorach fotografii" (Bredekamp 2004, s. 29; por. Welzer 2001, s. 17), a idąc śladem Susan Sontag możemy stwierdzić, że statyczne obrazy, czyli fotografie, mają znaczenie większe niż film i telewizja: „Fotografie potrafią zapaść w pamięć mocniej niż filmy, ponieważ rejestrują oddzielne jednostki czasu, a nie jego przepływ" (Sontag 2009, s. 25 i nast.) $)^{1}$. Aby dokładniej opisać ten zbiór wycinków „medium pamięci”, można ponownie zacytować Rolanda Barthesa (2008, s. 152): „Istotą Fotografii jest potwierdzenie tego, co przedstawia". Utrwala ona na stałe odbicie światła od fotografowanego obiektu. Obraz, nawet namalowany tak realistycznie jak fotografia, nie jest żadnym dowodem, że namalowany przedmiot kiedyś istniał, obraz może dowieść jedynie swego własnego istnienia. Fotograf natomiast był na miejscu i posługując się techniką sporządzania zdjęcia potwierdza jego przedmiot: „Ta rzecz tam była” (Barthes 2008, s. 137). W przypadku fotografii „jest podwójna wspólna płaszczyzna: realności i przeszłości” (Barthes 2008, s. 137). Albowiem $z$ wyznaczonej przez obiektyw współczesności wraz z zamknięciem przesłony na medium zapisującym pozostaje już tylko utrwalona przeszłość. Wydaje się więc, że fotografia jako taka jest wręcz medium pamięci.

Co więcej, za sprawą technicznego sposobu sporządzania obrazu uzyskujemy wrażenie, że owa miniona rzeczywistość nie tylko została przedstawiona autentycznie, ale wręcz obiektywnie uwierzytelniona. W akcie fotografowania bowiem, jak powiedział w 1844 r. Henry Fox, działa nie człowiek, lecz aparat: kamera pomaga naturze „zrobić sobie zdjęcie” (zob. Sachsse 2003, s. 13), ukazuje ona bowiem „prawdziwe i niezafałszowane pociągnięcie pędzla natury" (zob. Amelunxen, Iglhaut, Rötzer 1995, s. 15). Sposób, w jaki wczesna fotografia sama siebie pojmowała, wykazuje wielką zbieżność z naukowym ro-

1 Zob. też: Sontag 2010, s. 30: „Pamięć działa na zasadzie stopklatki: jej podstawową jednostką jest pojedynczy obraz". 
zumieniem historyzmu, który - według Leopolda von Rankego - niejako obiektywnie rości sobie prawo do mówienia, jak też to było w rzeczywistości. Podobnie jak odbicie światła zapisuje się na magazynującym informacje medium, tak samo historyczna rzeczywistość odciska się jak „pieczęć w wosku” (Goertz 1995, s. 43). Historyzmowi i pierwszym wypowiedziom teoretycznym na temat fotografii wspólna jest ta pozytywistyczna postawa. Poznawany obiekt należy (za pomocą światła lub pisma) uchwycić (po grecku graphein: za-pisać), a podmiot poznający i jego perspektywę $\mathrm{w}$ danym momencie - niezależnie od tego, czy jest to historyk czy fotograf - pominąć, jego usytuowanie jest ponad- lub pozahistoryczne. W obliczu tak naszkicowanego pokrewieństwa poznawczego nie dziwi, że Ranke właśnie fotografie uważa za „najprawdziwsze, najbardziej bezpośrednie dokumenty" (cyt. za Hartewig 2002, s. 428), świadczące o tym, co minęło.

Johann Gustav Droysen, historyk współczesny Rankemu, w rozprawie Historik z roku 1882 również przekazuje pewną uwagę o fotografii jako źródle. Ujawnia ona raczej krytyczne stanowisko wobec tego medium. „Podobieństwo fotografii jest najlichszego rodzaju, prawidłowe, ale nieprawdziwe” - twierdzi Droysen $(1977$, s. 87). Nie wyjaśnia on tego zdania, lecz rozróżnienie między „prawidłowym” i „prawdziwym” stanowi wskazówkę sugerującą jakąś różnicę. Szansa generowania naukowej „prawdy” historycznej wynika $z$ trafnego zastosowania metody historycznej w badaniach empirycznych. Historiografia opracowuje odmienne czasowo fakty z przeszłości, tworząc narrację o współczesnym znaczeniu. Fotografii zaś jako medium brakuje ważnej cechy: utrwalając ułamek sekundy nie ma ona możliwości różnicowania czasu. Nie może pokazać tego, co było przedtem i potem, uwiecznia tylko jeden moment ${ }^{2}$. Nie może wizualizować ważnych stosunków przyczynowo-skutkowych zachodzących w czasie i nie jest wyposażona w żadne reguły (gramatykę), pozwalające łączyć unormowane znaki (słownictwo) i przez to w sposób skonwencjonalizowany generować znaczenie (semantyka). Fotografia nie potrafi więc na przykład wizualizować trybu przypuszczającego, nie umie nic powiedzieć o częstości występowania, nie może wyrazić zaprzeczenia ani też czasu przyszłego. Ze zdjęcia nie można też wywnioskować, czy przedstawia ono coś reprezentatywnego. Jednakże fotografia potrafi uchwycić szczegóły chwili i dać ich ostry obraz, a więc „prawidłowo” przekazać bogactwo detali. Z perspektywy nauk historycznych oznacza to: fotografie nie opowiadają żadnej historii, można $z$ nich korzystać jako ze źródeł, podobnie jak z innego rodzaju pamiątek przeszłości, by pisać/opowiadać historię (historie). Jeśli przeszłość w ogóle da się reprezentować, a więc we właściwym sensie tego słowa uwspółcześnić, to można by to tak ująć: fotografia re-prezentuje przeszłość, nauki historyczne re-kontekstualizują fotografię jako źródło i re-konstruują przeszłość jako historię.

2 To różni fotografię od innych form przedstawień wizualnych. Malarz może na przykład na jednym obrazie przedstawić różne okresy. 


\section{FOTOGRAFIA I PRZYSZŁOŚĆ}

Specyfika fotografii wynika więc, według Barthesa, ze szczególnego powiązania rzeczywistości i przeszłości. To ontologiczne określenie statusu fotografii można jednakże zestawić z rozmaitymi jej funkcjami. Zalicza się do nich bez wątpienia retrospektywne świadczenie o przeszłości. Mają się one wiązać również z zamiarem projekcyjnego wywoływania działań i postaw oraz wywierania na nie wpływu. Widać to w przypadku fotografii reklamowej, najważniejszego segmentu nowoczesnej produkcji fotograficznej ${ }^{3}$. Według Barthesa, uwierzytelnia ona wprawdzie minioną rzeczywistość, faktycznie jednak wizualne obrazy przeszłości mają być ożywiane w przyszłości i wpływać na przyszłe decyzje o kupnie. Są to więc obrazy o funkcji raczej projekcyjnej niż retrospekcyjnej. Podobnie jest z komunikacją polityczną, która ma na celu pozyskanie dzięki mediom akceptacji w szerokich kręgach społeczeństwa. Posługując się zdjęciami irackiego dyktatora Saddama Husajna, przedstawiającymi go podczas zatrzymania w ziemnej norze czy badania zębów, Stany Zjednoczone uprawiały celową politykę - symbolicznie wizualizowały faktyczne pozbawienie dyktatora władzy i uświadamiały to całemu światu. Zgryzu dyktatora nie można bowiem pokazywać publicznie, chyba że nie jest on już dyktatorem. Również zdjęcia $z$ demontażu pomnika Saddama Husajna w Bagdadzie służyły wizualizacji zwycięstwa ${ }^{4}$, podobnie jak zainscenizowane pojawienie się prezydenta Stanów Zjednoczonych George’a W. Busha niemal jak zbawiciela na amerykańskim lotniskowcu „Abraham Lincoln” 1 maja 2001 r., gdy ogłosił on całemu światu wiadomość: Mission accomplished. Fotografia Larry'ego Drowninga (Reuters) ukazuje go $z$ aluzją aureoli oraz dwoma teleprompterami po bokach, jako figuratywnymi elementami przywodzącymi na myśl baldachim, pod którym $\mathrm{w}$ tradycji ikonograficznej sytuowany jest zazwyczaj wybraniec ${ }^{5}$.

Wyraźnie widać stosunek zdjęć do przyszłości w kontekście asymetrycznych wojen, w których strategia komunikacyjna polega na rekompensowaniu niższości militarnej przez pokazywanie zdjęć budzących grozę (Münkler 2006). Zdjęcia z egzekucji jeńców są wykorzystywane w charakterze broni tak samo jak Twin Towers walących się po uderzeniu w nie dwóch uprowadzonych samolotów. W ten sposób strona porywaczy, posiadająca minimalne zasoby wojskowe, wywołuje przerażenie na całym świecie i prowokuje do dalekosiężnych decyzji politycznych. Gerhard Paul, historyk z Flensburga, powołując się na Horsta Bredekampa, wezwał nauki historyczne, by nie skupiały wysiłków analitycznych wyłącznie na paradygmacie reprezentacji. Należy badać obrazy nie tylko

\footnotetext{
3 O badaniach nad rolą obrazu w reklamie zob. Schierl 2005, s. 309-319.

4 Zob. Bredekamp 2010, s. 226-233. Zakryta twarz świadczy wszakże o obawie przed spojrzeniem dyktatora.

5 Zob. w związku z tym Paul 2005; na temat symboli w polityce i wizualnej inscenizacji zob. Grittmann 2007, s. 155-173.
} 
jako pasywne źródła z przeszłości, ale też w ich aktywnej funkcji — „aktu” tworzenia zdjęcia, prowokującego do działania lub stanowiącego część działań lub strategii postępowania.

Tego rodzaju historiograficzne badanie obrazu jako aktu winno zająć się trzema dziedzinami: komunikacją polityczną (propaganda), polityką pamięci i polityką historyczną oraz historiograficznym badaniem tożsamości (Paul 2011, s. 7-22).

\section{PRZESZŁOŚĆ - FOTOGRAFIA JAKO INDEKS}

Z perspektywy historii nauki oprócz wspólnoty czasów „ojców” nauk historycznych w Niemczech i fotografii we Francji, Rankego i Daguerre'a, widać jeszcze jedną frapującą zbieżność: w tym roku, w którym został opublikowany pierwszy dagerotyp, w Stanach Zjednoczonych Ameryki urodził się semiotyk Charles Sanders Peirce. Zbieżność ta jest interesująca, ponieważ ogólna teoria znaku Peirce'a, nawet jeśli on sam fotografię wymienia jedynie na marginesie, od lat sześćdziesiątych i siedemdziesiątych XX wieku wywiera niezwykle silny wpływ na dyskurs teoretyczny o fotografii, ba, niemal go zdominowała ${ }^{6}$.

Tyle że obrazy (także zdjęcia) nie mogą być bezwarunkowo traktowane jako znaki, ponieważ ich specyfika, podobnie jak ich wizualne wyzwanie, znajdują się akurat poza przypisywaną im „znakowością” ${ }^{7}$. Klasyfikacja znaków według Peirce'a ma jednak kilka zalet przy wysuwaniu argumentów na rzecz specyfiki zdjęć: po pierwsze, może pomóc lepiej zrozumieć sposób posługiwania się zbiorowym zasobem zdjęć, po drugie, może przyczynić się do wyraźniejszego ujęcia statusu fotografii jako źródła historiograficznego w epoce cyfrowej. Dlatego zwięźle naszkicuję klasyfikację Peirce'a, a następnie ją zastosuję. Peirce rozróżnia trzy rodzaje znaków: ikony (znaki ikoniczne), indeksy (znaki indeksalne) i symbole (znaki symboliczne). Ikona cechuje się przede wszystkim tym, że między znakiem a tym, co reprezentuje, istnieje analogia lub podobieństwo - dotyczy to więc grosso modo na przykład obrazów realistycznych. Przedstawiony pies wygląda jak pies rzeczywisty. W przypadku symbolu zaś związek między znakiem i oznaczanym przedmiotem ma charakter wyłącznie konwencjonalny. Kolejność liter w słowie „pies” nie wykazuje żadnego podobieństwa $z$ tak określanym zwierzęciem. Istnieje wyłącznie umowa, że takie połączenie znaków (dystynktywnych) odnosi się do tego właśnie zwierzęcia domowego. Pismo reprezentuje więc tę klasę znaków, jakimi są symbole. Definicja trzeciej klasy znaków, indeksów, w pewnym sensie uprzedza - mimo wszystkich różnic — podaną kilkadziesiąt lat później przez Barthesa charakterystykę fotografii. Związek między indeksem a przedmiotem ma charakter przyczynowy, niemal

${ }^{6}$ Herta Wolf (2002, s. 16) pierwszy tekst, w którym przedstawiona była fotografia jako medium przede wszystkim indeksykalne, datuje na rok 1963.

7 Wielkie trudności powoduje na przykład wyizolowanie na obrazie znaków dystynktywnych. 
fizyczny. Na przykład: odcisk stopy istnieje dlatego, że stopa pozostawiła go w piasku. Wprawny tropiciel śladów może odczytać ten znak i podążyć za dzikim zwierzęciem. Oparzenie słoneczne powstaje dlatego, że promienie ultrafioletowe wywołują zaczerwienienie skóry. Lekarz potrafi odczytać ten znak i pomóc pacjentowi swoją fachową ekspertyzą. Albo - i to stanowi związek $z$ fotografią — znak powstaje dlatego, że promienie świetlne utrwalone zostają na światłoczułej warstwie nośnika.

Ikona jako rodzaj reprezentacji odpowiada więc prototypowo malarstwu (realistycznemu), symbol pismu, a fotografia indeksowi. Specyfika fotografii polega jednak na tym, że - w przeciwieństwie do innych sposobów reprezentowania - może ona łączyć w sobie wszystkie trzy właściwości, choć nie jest to absolutnie konieczne. W przypadku fotografii analogowej zawsze mamy do czynienia z indeksem. Może ona jednak też, pod warunkiem wystarczającej ostrości obrazu, być ikoną. I wreszcie: fotografii można nadać funkcję zbiorowego symbolu. Zdjęcie wybuchu bomby atomowej w Hiroszimie 6 sierpnia 1945 r. w Europie reprezentuje zatem niebezpieczeństwo atomowej apokalipsy, a w Stanach Zjednoczonych długi czas wyrażało potęgę militarną, naukową lub libidynalną. Również obraz może przejąć funkcję symbolu — pomyślmy choćby o Wolności wiodacej lud na barykady Eugène’a Delacroix. Obraz może być także ikoną, jeśli podobieństwo jest wystarczające, ale nigdy indeksem, ponieważ to, co przedstawia, nie znajduje się $\mathrm{w}$ żadnym przyczynowo-skutkowym, fizycznym stosunku z przedstawianą rzeczywistością. Pismo wreszcie zawsze jest tylko i wyłącznie symbolem ${ }^{8}$.

Jaki więc związek istnieje między dominacją paradygmatu indeksu w fotograficznym dyskursie teoretycznym i historycznym ostatnich dziesięcioleci $z$ jednej strony a naukami historycznymi $z$ drugiej? Poniższa propozycja sprawia wrażenie dość sensownej ${ }^{9}$. W obliczu epistemologicznych dyskusji ponowoczesności o możliwościach i zakresie historycznego poznania historiografii grozi utrata właściwego przedmiotu: mianowicie historycznego odniesienia. Wobec linguistic turn, (radykalnego) konstruktywizmu, (post)strukturalizmu, analizy dyskursu, kognitywistyki i kontrowersji wokół faktów i fikcji w dziejopisarstwie wygląda na to, że pod względem epistemologicznym definitywnie został zablokowany naukowy dostęp do przeszłości. „Jedyna rzeczywistość według jednej linii argumentacji w tej dyskusji w ostatnich dziesięcioleciach - z którą historyk ma do czynienia, to teraźniejszość" (Rusch 1997, s. 57; por. Goertz 2001, s. 97). Ta argumentacja przywodzi na myśl Droysena, który w swej „Historyce” $z$ drugiej połowy XIX wieku stwierdzał: „To, co jest dane

\footnotetext{
$8 \mathrm{~W}$ wyżej określonym sensie, ale pismo jako tekst może też być symbolem. Biblia bowiem jako tekst kanoniczny symbolizuje chrześcijaństwo, a Koran islam.

9 „Myślenie o śladzie całą mocą dyskursu opiera się ponowoczesnej utracie zagwarantowanej referencjalności, zawartej w obietnicy bezpośredniego kontaktu znaków indeksykalnych" (Löffler 2010, s. 98).
} 
w badaniach historycznych, to nie miniona przeszłość, bo ta minęła, lecz to $z$ niej, co tu i teraz jeszcze nie przeminęło, choćby wspomnienia o przeszłości lub pozostałości po tym, co było i co się zdarzyło" (Droysen 1977, s. 422).

I w obliczu tej „niepewnej historii” (Goertz 2001) wydaje się, że indeks gwarantuje, wręcz przyrodoznawczo, to, co ponowoczesne myślenie jakoby bezpowrotnie utraciło. Połączenie oddziaływania fizycznego i chemicznego utrwala promień światła, który tym samym rzeczywiście reprezentuje $\mathrm{w}$ teraźniejszości przeszłość. Historyczny odsyłacz jest te raz obecny, fotografia bowiem go pokazuje: „jedno jest przyklejone do drugiego”, według Barthesa (2008, s. 14). Argumentuje on niemal esencjonalistycznie, mówiąc mianowicie, że zdjęcie jako reprezentacja przeszłości jej nie re-prezentuje, ale raczej jest tym, co przedstawia z przeszłości. Inaczej niż u Pierce’a zdjęcie nie jest już znakiem znaczonego, lecz „samą rzeczą” (Ullrich 1997, s. 65; Geimer 2009, s. 36 i nast.). „Faktycznie - pisze Barthes (2008, s. 13) — określone zdjęcie nigdy nie odróżnia się od swego przedmiotu odniesienia (od tego, co przedstawia)”; stanowi „emanację rzeczywistości minionej” (Barthes 2008, s. 99).

\section{HISTORIA KULTURY — FOTOGRAFIA JAKO IKONA}

To skupienie się na indeksykalnym statusie fotografii wykazuje jednak przynajmniej dwie słabości (Wittmann 2010). Zaniedbuje, tak jak już w dziewiętnastowiecznej autorefleksji fototeoretycznej nie dającą się pominąć perspektywiczność obrazu. Polega ona z jednej strony na usytuowaniu autora zdjęcia, $z$ drugiej na perspektywicznym ujęciu obrazu, a wreszcie wynika $z$ technicznego programu aparatu fotograficznego. Bezpośrednio wiąże się $z$ tym wygaszanie ikoniczności obrazu i jego semantycznej pełni.

Autor zdjęcia ma możliwości wyboru tematu obrazu (kieruje się motywami zleceniodawcy lub własnymi) oraz jego ujęcia (kompozycja, perspektywa itd.). Każdorazowy wybór komponentów może być odmienny, ale muszą one zaistnieć. Bez nich widać byłoby jedynie białą powierzchnię. „Niezbędność formy estetycznej, jej własna rzeczywistość, jawi się jako coś danego sui generis (Krüger 1997, s. 56). To nie przypadek, że właśnie historia sztuki ze swoim badaniem for my obrazu jest krytyczna wobec paradygmatu indeksu. „Archaiczne pojmowanie fotografii - jak twierdzi historyk sztuki Wolfgang Kemp (2006, s. 151) - jako odcisku samej siebie — jest wypróbowanym środkiem do umniejszania uczestnictwa fotografa”. Opłaca się „wkalkulować historyczną świadomość fotografa". Paradygmat indeksu, skoncentrowany na fizyczno-chemicznym związku obiektu sfotografowanego $z$ fotografowanym, "przeskakuje” niejako nie tylko fotografujący podmiot, ale też i aparat fotograficzny. Aparat zaś nie produkuje „obiektywnych” obrazów świata, lecz realizuje jedynie, według Viléma Flussera, wmontowane weń możliwości techniczne. Jest „zaprogramowany do sporządzania fotografii, a każda fotografia to realizacja jed- 
nej z możliwości zawartych w programie aparatu. Liczba tych możliwości jest wielka, lecz skończona" (Flusser 1997, s. 24).

Na konieczność analizowania formalnego kształtu obrazu wskazywali również od czasu do czasu historycy i medioznawcy. Choćby Martina Heßler (2005, s. 272) stwierdza, że historycy traktują „zdjęcia $z$ reguły jako dokument historyczny, nie zajmując się nimi jako zdjęciami. Ich forma, estetyka, warunki produkcji, narzędzia ich sporządzania, charakter inscenizacyjny oraz specyficzne dla zdjęcia środki wyrażania sensu $z$ reguły nie budzą zainteresowania. Zdjęcia czytane są przeważnie "treściowo», bez uwzględniania roli estetyki w nadawaniu znaczenia fotografii". Podobnie wypowiadają się historycy i medioznawcy Fabio Crivellari i Markus Sandl (2003, s. 643) w rozważaniach na temat „medialności historii”. Chodzi o to, żeby „traktować obrazy nie jako nie uczestniczące w transformacji dokumenty prezentowanej «treści», lecz interpretować je zgodnie z kryteriami opracowanymi zwłaszcza w naukach o sztuce i w historii sztuki. Przez świadome zwrócenie się ku "gramatyce» takiego medium, jakim jest «obraz", podejmuje się próbę odkrywania warstw znaczeniowych, które konwencjonalna krytyka źródeł, nastawiona jedynie na treść obrazu, traci z pola widzenia". Analitycznym spojrzeniem należy więc objąć własny, ikoniczny sens obrazów - i to nie wyłącznie jako estetyzację spraw historycznych, jako w pewnym sensie „pozbawione znaczenia” zapośredniczenie w przekazie. W refleksji nad stosunkiem sztuki i historii Klaus Krüger, historyk sztuki, podkreśla semantyczne znaczenie aspektu ikonicznego: „Właśnie owe «niemimetyczne» elementy przedstawienia pozwalają wprowadzić wartości pojetyczne i liryczne oraz polityczne i duchowe znaczenia, których przejrzystość tego przedstawienia nie musi uwzględniać" (Krüger 1997, s. 74). Dyskursywny wysiłek opisania dystynktywnych cech fotografii jako oddzielnego typu w rodzinie wszystkich obrazów wiąże się więc z wysokimi kosztami. Abstrakcja i redukcja prowadzą, jak to zostało opisane wyżej, do pomijania pewnych aspektów w analizie oraz do sprzeczności. Skupiając uwagę na statusie indeksykalnym, pomijamy różnicę jakościową między na przykład oparzeniem słonecznym a fotografią. Oba zjawiska stanowią bowiem wizualny wyraz jakiegoś odcisku. Jednakże definiowanie specyfiki fotografii przez właściwość, która daje się zastosować również $\mathrm{w}$ odniesieniu do niefotograficznych zjawisk wizualnych, sprawia, że definicja staje się niespójna i niewiele znacząca. Ponadto obraz podlega kastracji pod względem semantycznym. Paradygmat indeksu argumentuje następująco: „fotografia nie wyjaśnia, nie interpretuje i nie komentuje. Jest niema i naga, płaska i głucha. Inni mówią, że głupia. Po prostu brutalnie i bezwzględnie pokazuje nam znaki semantycznie puste lub banalne" (Dubois 1998, s. 56). Fotografię otacza „brak znaczenia [...], który można wypełnić jedynie przez dodanie jakiegoś tekstu". Ten rodzaj argumentacji jest w gruncie rzeczy ikonoklastyczny - nie zauważa ikoniczności i semantyki w tym, co jest specyficznie ikoniczne, i podporządkowuje obraz prymatowi języka. Tylko on bowiem może nadać obrazowi sens. Obrazy, a także fotografie, są wprawdzie nieme, ale nie 
pozbawione znaczenia. Nadawanie znaczenia przez obraz i obrazem nie jest wyłącznie wynikiem projekcji oglądającego, ale zawdzięczamy je również formalnemu kształtowi obrazu, a więc jego estetyce. Niemiecki teoretyk historii Jörn Rüsen (1994, s. 12) zwraca uwagę na kategorię wymiaru estetycznego mówiąc, że „pamięć świadomości historycznej działa w naturalny i specyficznie estetyczny sposób, rządzi się własnymi prawami, i nie można jej podciągnąć pod kognitywny i polityczny kształt pamięci historycznej".

\section{KULTURA HISTORYCZNA — FOTOGRAFIA JAKO SYMBOL}

W kontekstach kultury historycznej obrazy-klucze lub fotoikony ${ }^{10}$ rozumie się odmiennie niż $\mathrm{w}$ argumentacji indeksowej — przede wszystkim jako symbole, jako „prawdziwe znaki”. Odwołując się do Pierce’a, można sformułować to tak: jako indeks kanoniczne fotografie uczestniczą w sugerowaniu obiektywizmu, oczywistości i „prawdy”. W recepcji dnia codziennego właśnie one funkcjonują jak „wehikuły rzeczywistości, ułatwiające orientację i gromadzące wspomnienia" (Lethen 2004, s. 70). Jako część składowa pamięci zbiorowej kanoniczne zdjęcia urastają do rangi symbolu wydarzeń historycznych, a związane $z$ nimi kolektywne narracje, powtarzane przez każdą dystrybucję i repetycję obrazów, sprawiają, że interpretacje historyczne stają się udziałem większości i trwają, przez co powstaje i stabilizuje się zbiorowa tożsamość i legitymizacja. Jan Assmann (2000, s. 120) uważa bowiem, że „każdy akt recepcji jest zarazem opowiadaniem się za jakąś specyficzną hierarchią wartości”. Obrazy-klucze przywołują władze państwowe (przez pomniki, na znaczkach pocztowych, $\mathrm{w}$ muzeach itd.) w celu ugruntowania ważnych dla tożsamości interpretacji służących integrowaniu społeczeństwa. Filozof Peter Sloterdijk w tym właśnie upatruje „znaczenia i funkcji obrazów. Zaczarowują one ludzi we wspólnoty” 11.

W kontekście kultury historycznej tego rodzaju źródło fotograficzne jako „skrót narracyjny” (Jörn Rüsen) doświadcza nobilitacji, stając się symboliczną narracją, i w kulturze pamięci pełni funkcję normy; pokazuje i „mówi” nam jako mnemotechniczny imperatyw: Przypomnijcie sobie tę ważną historię! W popularnych publikacjach tego rodzaju postulat występuje $w$ tytułach, takich jak tytuł albumu „Obrazy Niemców. Co nas łączy, co nas porusza” (Thiele 2005) czy serialu nadawanego przez program drugi telewizji niemieckiej „Niemcy. Kim byliśmy - kim jesteśmy". W argumentacji chodzi tutaj implicite nie o przeszłość, lecz o zagwarantowanie przez politykę tożsamościową egzystencji w przyszłości. Przeszłość „wykorzystywana jest jako źródło surowca do produkcji narracji tworzącej znaczenia, dającej orientację i spójność" (Gudehus,

\footnotetext{
10 W kwestii terminologii zob. Hamann 2007, s. 39-49; por. Hamann 2011, s. 23-35.

11 „Das Bild ist immer um eine Dimension pflingstlicher als die Schrift”, wywiad Herberta Burdy z Peterem Sloterdijkiem, w: Burda 2010, s. 90; por. też: Assmann 1999, s. 132: „Przez wspólne symbole jednostka uczestniczy we wspólnej pamięci i wspólnej tożsamości".
} 
Eichenberg, Welzer 2010, s. 7 i nast.), by wpływać na postrzeganie teraźniejszości i kształtować nastawienie na przyszłość. „Poznawczym punktem odniesienia dla pamięci jest przyszłość, w żadnym razie [...] nie przeszłość (Gudehus, Eichenberg, Welzer 2010, s. 9). Bez wątpienia takie podejście programowe związane $z$ obrazami powoduje dylematy w heterogenicznych wspólnotach pamięci, w których jest wprawdzie wiele wspomnień, ale coraz mniej wspólnoty. Jak bowiem narracje jakiejś stosunkowo homogenicznej (kulturowo, etnicznie...) przeszłości zdołają sprostać dążeniom politycznym do integracji we współczesnych heterogenicznych warunkach? Ponadto: inkluzja i ekskluzja wzajemnie się warunkują. Odwrotną stroną autodefinicji jest zaklasyfikowanie (ewentualnie implicite) tych, którzy do nas nie należą. Jeśli ma istnieć jakaś polityka tożsamościowa, to musi ona budować na dywersyfikacji realnie istniejącej we współczesności.

W łańcuchach recepcji w ramach kultury historycznej mogą się znajdować również wizualne ogniwa powodujące alienację obowiązujących reguł normatywnych, stosujące je $z$ ironią, a tym samym uprawiające wobec nich krytyczną refleksję lub dekonstrukcję. Podczas gdy motyw Iwo Jimy jako wizualizacja amerykańskiego patriotyzmu w Stanach Zjednoczonych, na przykład na znaczkach pocztowych, i USMC War Memorial na cmentarzu w Arlington są wykorzystywane przez państwo w kulturze pamięci, tygodnik „Der Spiegel” ten motyw stosuje na okładkach w zupełnie innych kontekstach. Posługuje się nim jako metaforą zdecydowania i zdobywania, odnosi do takich tematów jak Bundeswehra i ONZ, nauczanie i szkoła lub obawa przed Niemcami na Majorce ${ }^{12}$. Karykaturzysta Klaus Stuttman zaś przywołując Iwo Jimę wizualizuje zamiar wycofania się Amerykanów z Iraku. Żołnierze u niego nie wbijają drzewca flagi w ziemię iracką, nie, oni je wyciągają, a na fladze widnieje napis: „Bye, bye Iraq!” 13. Podobnie krytyczną postawę formułuje inna reinscenizacja motywu - pięciu mężczyzn w podeszłym wieku stawia zwęglone drzewce $z$ flagą Stanów Zjednoczonych (Braschler, Fischer 2007, s. 15). Również filmy fabularne, takie jak Piaski Iwo Jimy (1949) z Johnem Waynem w roli głównej lub Listy z Iwo Jimy (2006) Clinta Eastwooda stanowią wariacje na temat tego motywu. Edward Kienholz z kolei w swym Portable War Memorial posługując się motywem Iwo Jimy krytykuje politykę Stanów Zjednoczonych wobec Wietnamu, a grupa hiphopowa Wu-Tang Clan na okładce płyty „Iron Flag” (2001) przedstawia ten motyw z udziałem czarnych żołnierzy, by zademonstrować samoświadomość Afroamerykanów ${ }^{14}$.

Liu Shaoqi oddaje cześć Shi Chuanxiong za opróżnianie pekińskich toalet, lub Chinska supergirl z panda — jogurt z mongolskich krów 2005 to obrazy-legendy,

12 „Der Spiegel” z dnia 24 sierpnia 1994, 30 stycznia 1995, 2 sierpnia 1999.

13 „Der Tagesspiegel”, 2 września 2010, s. 8.

14 Ten i dalsze przykłady obrazów zob. Hamann 2007, s. 238-251; por. Hariman, Lucaitis 2007, s. 93-136. 
będące częścią zbiorowej pamięci 1,3 miliarda ludzi. Ale w Europie prawie nikt ich nie zna, ponieważ są elementem zbiorowego wykorzystywania zdjęć $\mathrm{w}$ Chinach ${ }^{15}$. To stwierdzenie dobrze pokazuje, że kolektywne posługiwanie się obrazami stanowi konstrukcję dynamiczną. Jego analiza powinna uwzględniać obszary rozpowszechniania zdjęć, ich wzajemne odgraniczanie się lub nakładanie, aż po globalny kanon obrazów. Zasięg stosowania fotografii można mierzyć albo według parametrów tradycji kulturowej, albo też zakładając genealogiczne lub społecznie różne rodzaje pamięci. Wymienione wyżej chińskie obrazy-klucze artysta Michael Schirner wydestylował w swoim projekcie „Obrazy w głowie Chińczyka”. Metoda, którą zastosował już w 1985 r. na pewnej wystawie, uświadamia zwiedzającemu, jakie ma on "obrazy w głowie” (Schirner 1987). Ta wystawa fotograficzna nie pokazywała ani jednego zdjęcia, lecz wyłącznie czarne powierzchnie opatrzone legendami. Legendy przywoływały pamięć o kanonicznych zdjęciach i sprawiały, że pojawiały się one w głowach patrzących (Schirner 2007, s. 57-64). Jakieś dziesięć lat po wystawie Schirnera weimarski Bauhaus-Universität, $z$ inicjatywy Schirnera stosując tę samą metodę, odkrywał „obrazy w głowie obywateli NRD” (Holzwarth, Gamper 1998), a w 2009 r. również kuratorzy wystawy „60 lat 60 dzieł. Sztuka z Republiki Federalnej 1949 do 2009” sięgnęli po nią, opatrując wystawę tytułem „Czarne obrazy" 16 . To porównanie po raz kolejny pokazuje, że kolektywne operowanie obrazami to konstrukcja dynamiczna. Zdjęcia reklamowego „Gruba z reklamy Fuji/Światło słoneczne” (Christian von Alvensleben, 1972) z hamburskiej wystawy „Sterna” z 1985 roku nie znają ani Niemcy o biografii enerdowskiej, ani młodsi obywatele Republiki Federalnej. Natomiast „Żołnierz NVA, uciekający w pełnym umundurowaniu przez druty kolczaste na Zachód" (Peter Leibing, 1961) znalazł się w galerii zdjęć w 1985, 1998 i też 2009 roku. Z kolei w ogóle nic nie mówi mojemu krewnemu urodzonemu w 1989 roku zdjęcie porwanego i zamordowanego przez Frakcję Czerwonej Armii w roku 1977 prezesa Niemieckich Związków Pracodawców (BDA) Hannsa Martina Schleyera.

Jak więc można podsumować kwestie procesów powstawania kanonu? Dzięki częstości i długiemu okresowi ich pokazywania oraz szerokiemu rozprzestrzenieniu $\mathrm{w}$ mediach $\mathrm{w}$ jakiejś pojedynczej (ale też czasem globalnej) wspólnocie pamięci zdjęcia fotograficzne stają się bardzo znane i (w sensie Pierce'a) zyskują status symbolu. Są one wielokrotnie reprodukowane w wielu dziedzinach, w sztuce, w mediach, w konsumpcji, w codzienności i wspomnieniach. Powiązania intersektoralne i powtórzenia potwierdzają wzajemnie oczywiste istnienie tego, co się widziało, i znaczenie symbolicznej narracji oraz norm. Kolektywne posługiwanie się obrazami to zarazem dynamiczne

15 Mich gibt es gar nicht. Markus Peichl im Gespräch mi Michael Schirner, w Schirner, 2010, s. 156; por. Schirner 2007, s. 57-64.

16 „60 Jahre 60 Werke. Kunst aus der Bundesrepublik Deutschland 1949-2009”, Martin-Gropius-Bau, Berlin 1 maja - 14 lipca 2009. 
konstrukcje podlegające stałym zmianom. Obrazy-klucze jako ikona sięgają ponadto do tradycji ikonograficznych (formuły patosu, symbolika chrześcijańska...), podobnie jak do ponadczasowych podstawowych tematów ludzkiej egzystencji (moc - niemoc, wstyd, seksualność...). Często układ obrazu cechuje się formalną sugestywnością (Hellmold 1999, s. 34-50). Ponadto obrazy reprezentują momenty historyczne, które mają znaczenie dla danej wspólnoty pamięci ${ }^{17}$. Obrazy-klucze łączą w sobie cechy wszystkich trzech klas znaków w terminologii Peirce'a - są na równi ikoną, indeksem i symbolem.

\section{FOTOGRAFIA CYFROWA — OD INDEKSU DO IKONY}

W 150 rocznicę swych urodzin pewna epoka techniczna chyba się skończyła. Od roku 1989 bowiem, a więc półtora wieku po opublikowaniu w 1839 r. pierwszego dagerotypu, upowszechnia się fotografia cyfrowa (Schröter 2004, s. 344 i nast.). W mediach, sztuce, dyskursie teorii i historii fotografii szaleje „wojna pozycyjna "technofetyszystów» $z$ "obrazoburcami»" (Bruder 2010, s. 4). Z jednej strony sformułowania typu „koniec epoki fotografii” (Wolf 2002) lub „fotografia po fotografii" (Amelunxen, Iglhaut, Rotzer 1995) świadczą o powszechnym postrzeganiu cezury poznawczej ${ }^{18}$. Specyfika zdjęcia fotograficznego staje pod znakiem zapytania. Nie ma już bowiem żadnej gwarancji indeksu, brak jest (historycznego) odniesienia i otwarte na oścież są drzwi do możliwości manipulowania cyfrowym obrazem. Peter Lunefeld (2002, s. 163) stwierdza, że między fotografią analogową i cyfrową nastąpiło „radykalne zerwanie”, a historyk fotografii Timm Starl (2002, s. 73-77) uważa, że w epoce cyfrowej należy zrezygnować z pojęcia „fotografii dokumentalnej”. Fotografie cyfrowe są „postfotograficzne [...], nie mają już charakteru fotografii weryfikującej coś dziejącego się na świecie" - twierdzi Timothy Druckrey (cyt. za: Rötzer 1995, s. 13), podobnie jak Jean Baudrillard, który sądzi, że „W syntetycznym obrazie [...] znikła już rzeczywistość” (cyt. za: Kemp, Amelunxen 2000, s. 258).

Inne głosy natomiast są wyrazem zdenerwowania „wprost nieustannym gadaniem o (rzekomej) utracie realności we współczesnym postfotograficznym świecie” (Schröter 2004, s. 336). Za „apokaliptyczną tonacją” i „katastroficzną krytyką zdjęć", według Petry Löffler (2010, s. 87, 101), obok innych, kryją się także ekonomiczne kalkulacje rynku dzieł sztuki. Zdjęcia cyfrowe i komputer, jak z kolei zauważa Peter Sloterdijk w wywiadzie przeprowadzonym przez Herberta Burdę (2010, s. 92), dopiero stwarzają możliwość globalnej wspólnoty w epoce popiśmiennej. „Jeszcze raz przyjmujemy chrzest przez kąpiel w kom-

17 Do powstawania kanonu por. Fahlenbrach, Viehoff 2005, s. 369-372; Grittmann, Ammann 2008, s. 296-325. Do udziału ikoniczności w procesach powstawania kanonu por. Hamann 2007.

18 Dokładnie rzecz biorąc, podejrzenie nie kieruje się przeciwko digitalizacji jako takiej, lecz przeciw programom obróbki zdjęć, takim jak Adobe Photoshop, dostępny na rynku od lutego 1990 roku. 
puterach. W ogóle dopiero przez kulturę ikoniczną zyskujemy zdolność do stawania się członkami wspólnoty światowej".

Dla niektórych autorów różnica między fotografią analogową a cyfrową ma status wręcz ontologiczny, dla innych natomiast w najlepszym razie względny. Gwałtowny charakter dyskusji można interpretować jako nowe wydanie „platońskiego prastarego strachu przed konfrontacją z obrazem, nad którym nie da się zapanować" (Bredekamp 2004, s. 47) i tłumaczyć częstą podejrzliwością wobec (złudnych) obrazów, reprezentujących niejako tylko pozory, które nie odzwierciedlają żadnego istnienia jako jego „prawdziwe symbole”. Jednocześnie jest on implicite także wskaźnikiem głęboko zakorzenionej wiary w rzekomy obiektywizm i prawdę fotograficznego zdjęcia (Lunenfeld 2002, s. 167; Rötzer 1995, s. 21). W dziedzinie fotografii jednak nigdy nie istniał obiektywizm. Niezależnie bowiem od wszystkich odniesień do rzeczywistości fotografia, jak opisano wyżej, zawsze była, po pierwsze, subiektywną interpretacją świata, a po drugie, od samego początku podlegała zamiarom inscenizacji i obróbki, a nawet przeinaczania.

Każdy sąd o fotografii cyfrowej i każdy jej osąd należy do przepełnionego pola gry dyskursywnej i jest konsekwencją interesów poznawczych. Czy w centrum znajduje się przedmiot czy jego obraz? Wraz z tym pytaniem jeszcze raz powraca dawna dyskusja o statusie fotografii. Czy jest ona narzędziem nauki czy sztuki? Teoria sztuki na przykład z zadowoleniem wita digitalizację jako szansę na emancypację od fotografowanego obiektu, od światła i istniejących kolorów oraz jako możliwość użycia „cyfrowego pędzla” w „postprodukcji” zdjęcia (Rötzer 1995, s. 21). Dla historiografii jednak historyczna referencyjność stanowi conditio sine qua non jej samorozumienia jako nauki ${ }^{19}$. Nauki historyczne zachowują dotychczas powściągliwość wobec statusu cyfrowego współczesnej fotografii i nie włączają się do dyskusji o cezurze epistemologicznej. $Z$ reguły pojawiają się argumenty przedcyfrowe. W powszechnie używanych podręcznikach i opracowaniach przeglądowych z zakresu empirycznych badań historycznych (np. Hartewig 2002; Reichhardt 2006, s. 219-230; Burke 2001; Jäger 2009) i dydaktyki historii (np. Bergmann, Schneider 1999, s. 211-254; Sauer 2002; Wirsching 2006, s. 281-292; Hamann 2007; Pandel 2008; Handro, Schönemann 2008) refleksje na temat fotografii cyfrowej jako źródła historycznego nie odgrywają prawie żadnej roli. W historii fotografii w węższym ujęciu o toczonych sporach świadczą pojedyncze opracowania ${ }^{20}$, a źródłem impulsów jest tu przede wszystkim obszar angloamerykański (np. Ritchin 1999; Warner Marien 2002, a zwłaszcza Wells 2009; zob. też: Sachsse 2003). Zupełnie ina-

19 I tego nie zmienią też argumentacje z dziedziny teorii sztuki i mediów, ponieważ problem „prawdziwości” (w sensie obróbki po pierwszym naświetleniu) obrazu ma podrzędne znaczenie.

$20 \mathrm{~W}$ czasopiśmie „Fotogeschichte”, w artykułach poświęconych tematowi digitalizacji, stosowane są raczej argumenty z perspektywy teorii sztuki i historii techniki niż krytyki źródeł historycznych; zob. np. Ullrich 1997; Wyss 2000, s. 3-11; Schröter 2003. 
czej jest w powstającej teorii kulturoznawstwa, w medioznawstwie i naukach o sztuce lub w teorii fotografii. Począwszy od lat dziewięćdziesiątych XX wieku zajmują się one intensywnie digitalizacją w mediach i jej implikacjami (zob. Ritchin 1990, s. 28-37; Mitchell 1992; Amelunxen 1995; Wolf 2002, 2003; Maar, Burda 2004, 2006; Sachs-Hombach 2005; Dotzler 2010; zwięzłe podsumowanie: Geimer 2009).

Praktyka fotografii prasowej, a tym samym praktyka produkcji zdjęć jako źródeł dla historiograficznej przyszłości, od dziesięciu-dwudziestu lat w wysokim stopniu ma charakter cyfrowy (Grittmann, Neverla, Ammann 2008, zwłaszcza s. 19-24; por. Büllesbach 2008, s. 108-136). Jednocześnie w codziennej recepcji odróżnianie zdjęć analogowych od cyfrowych ma drugorzędne znaczenie. Mimo zmian w produkcji technicznej dla na-ocz-nego obserwatora nic się nie zmieniło, w codzienności konsumenta cyfrowa fotografia niczym się nie różni od analogowej. Nauka musi jednak uwzględnić tę zmianę, postawić pytanie o wartość źródłową fotografii cyfrowej w związku z programami obróbki zdjęć i przedyskutować konsekwencje metodyczne ${ }^{21}$.

Uświadomienie sobie zmian technicznych jest niezbędne i bardzo krótko je tu przedstawię. W przypadku fotografii cyfrowej utrwalenie światła dokonuje się dzięki wykorzystaniu nie światłoczułej emulsji, lecz światłoczułego chipu, który pozwala zmierzyć i zapisać natężenie światła w liczbach. Informacja o obrazie zostaje zatem uwolniona od specyficznego nośnika. Fotografia cyfrowa w przeciwieństwie do analogowej jest odwracalna i nie tylko może być skasowana bez śladu i pozostałości, ale też zmieniona w każdym szczególe (Hagen 2002, s. 233; Löffler 2010, s. 83). „Zdjęcia komputerowe — jak mówi Friedrich Kittler (2002, s. 179) — są wręcz możliwością przeinaczania” Cyfrowe zdjęcie można morfować, klonować, nakładać, filtrować, zmiękczać, wyostrzać, odbijać, odwracać, obracać, skalować, ściskać, rozciągać, kolorować, dodawać do niego efekty rastra i nawet tak długo obracać wokół jednego punktu, aż zacznie sprawiać wrażenie, jakby czarna dziura połknęła całą fotografię" (Lunenfeld 2002, s. 165).

Przekształcenie światła w pomiar powoduje, że zdjęcie można nie tylko przesłać i zapisać, ale też swobodnie nim manipulować. Dane uzyskane z pomiaru nie muszą bowiem być przedstawiane w postaci obrazu. Można je zamienić $\mathrm{w}$ dźwięk lub mogą się pojawić jako zwykły zbiór znaków dystynktywnych. W ten sposób ginie specyfika obrazowości, cechy fotografii „mieszają się [...] z cyfrową komputerową zupą z liter, liczb, grafiki mobilnej i plików dźwiękowych (Lunenfeld 2002, s. 164; por. Hagen 2002, s. 234; Löffler 2010, s. 83).

${ }^{21}$ Dotyczy to również masowej cyfryzacji zasobów analogowych zdjęć przez agencje i archiwa. Jeśli chodzi o indeksykalne zdjęcie sprzed produkcji cyfrowej, to historyk sztuki Beat Wyss (2000, s. 10 i nast.) proponuje chronić je przed zniszczeniem w wyniku digitalizacji albo przynajmniej zachować vintage print fotografii indeksykalnej. 
Stosując klasyfikację znaków według Pierce’a, można jednak nadal twierdzić, że fotografia o statusie cyfrowym tak samo jak fotografia analogowa dysponuje indeksykalnym powiązaniem $z$ historycznym przedmiotem odniesienia. Dopiero możliwość nie pozostawiającej śladów obróbki obrazu prowadzi do tego, że nie może już ona zagwarantować odniesienia do indeksu. Fotografia cyfrowa ma jednak nadal ten sam teoretyczny status znaku co (realistyczne) malarstwo i w ramach teorii znaku zmienia się $z$ indeksu w zwykłą ikonę ${ }^{22}$. Historyczny przedmiot odniesienia nie ulega przez to bynajmniej per se wymazaniu. Jedynie nie może być już uzasadniony przez indeks - wskazanie na chemię i fizykę nie nadaje się już, by udowadniać historyczną oczywistość. Lecz z punktu widzenia epistemologii także ikony są przydatne jako źródła w generowaniu historycznej „prawdy” lub „nieprawdy” 23. Również pismo (symbol w terminologii Peirce'a) nie ma żadnego odniesienia do indeksu ${ }^{24}$, mimo to historiografia się na nim opiera i w zasadzie nie kwestionuje tekstów źródłowych, tyle że wśród metod historycznych stosuje też krytykę źródeł ${ }^{25}$. Ze względu na niematerialny status fotografii cyfrowej odpada jednak zewnętrzna krytyka źródeł. Zgodnie z naturą rzeczy umniejsza to znaczenie metody historycznej. Ale nie jest ona zupełnie bezradna - by zwiększyć prawdopodobieństwo prawdziwości, należy zastosować immanentną analizę obrazu, która — jak w przypadku zdjęcia analogowego - zwraca uwagę głównie na wizualne niespójności (nieumotywowane kontrasty, cienie, źródła oświetlenia itd.) (Rötzer 1995, s. 23) ${ }^{26}$.

Obok sposobu autoryzacji przez krytykę źródeł nauka (i publiczność) skazana jest na zewnętrzną autoryzację cyfrowego obrazu. Musi jej dokonać sam autor lub instancje dystrybucji fotografii, na przykład archiwa, agencje i instytucje publikujące zdjęcia. Produkcja zdjęć przeznaczonych dla sfery publicznej podlega mechanizmom rynkowym i dlatego pokusa manipulowania obrazem staje się spora. Na pewno w różnych segmentach produkcji medialnej wymagania wobec fotografii są bardzo różne. Magazyny typu lifestyle żyją ze sprzedaży świata pozorów i kompatybilnych z rynkiem zdjęć ludzi nierealnej urody, wymagania co do autentyczności tych produktów są stosunkowo niewielkie. Odbiorca wie, o co tu chodzi, i ma inne oczekiwania wobec takich magazynów niż wobec dzienników ${ }^{27}$. Te $z$ kolei żyją $z$ wiarygodności swoich informacji, dlatego zwracają dużą uwagę na to, by ją zachować u czytelników. W związku $\mathrm{z}$ tym aby zapewnić pewne standardy $\mathrm{w}$ fotodziennikarstwie gazety $\mathrm{i}$ organizacje zawodowe, doprowadziły do sformułowania kodeksów honorowych.

22 Zakładając wystarczającą ostrość obrazu.

$23 \mathrm{~W}$ tym sensie stawiane są na równi z pismem; por. Lunenfeld 2002, s. 165-169.

24 Nie licząc techniki frottage, dzięki której na przykład odciska się pismo na nagrobku.

25 W dziedzinie fotografii analogowej zob. Kerbs 1989, s. 241-262.

26 O technicznych możliwościach stwierdzania obróbki zdjęć zob. Frank Thadeusz, Lichtpunkt im Auge, w: Spiegel online (http://www.spiegel.de/spiegel/0.1518.681010.00.html).

27 Badania empiryczne dowodzą, że czytelnicy najmniej akceptują manipulację obrazami w przypadku zdjęć ilustrujących wiadomości; zob. Büllesbach 2008, s. 108-135. 
Niemiecka Rada Prasowa zaleca na przykład: „Fotomontaż lub inne zmiany należy jako takie wyraźnie zaznaczyć w legendzie do zdjęcia lub w odnośnym tekście”. Agencja Associated Press ustala jednoznacznie: „Zawartość fotografii nigdy nie będzie podlegała zmianie lub jakiejkolwiek manipulacji". W kodeksie etycznym National Press Photographers Association w Stanach Zjednoczonych mamy podobnie wyraźne stwierdzenie o niedopuszczalności jakichkolwiek mogących zmylić odbiorcę zmian w dokumentalnych zdjęciach fotoreporterskich. Różne niemieckie organizacje fotografów uchwaliły w 1997 r. „memorandum o obowiązku oznaczania zdjęć manipulowanych" 28 . Rzecz jasna, nie wiadomo, jak wiele fotografii dziennikarskich ulega manipulacji. Znane stają się jedynie nieliczne przypadki, ale zwracają one uwagę opinii publicznej i pociągają za sobą określone konsekwencje. Gdy libański fotograf niezależny Adnan Hajj w 2006 r., podczas wojny w Libanie, nieznacznie zmanipulował zdjęcia z akcji sił zbrojnych Izraela, agencja Reutera, dla której Hajj pracował od dziesięciu lat, zerwała $z$ nim współpracę i wycofała $z$ dystrybucji wszystkie jego zdjęcia (Rötzer 2006). Prasa szeroko komentowała ten przypadek, który pokazuje, że medialna strefa publiczna internetu otwiera zarazem większe możliwości krytycznej kontroli.

Z perspektywy badań historiograficznych pojawiają się również problemy technicznych warunków archiwizacji. Elektronicznie-cyfrowy hardware ma coraz krótsze okresy aktualności i długookresowa archiwizacja zdjęć cyfrowych napotyka granice stale odnawiającej się techniki zapisu (Grittmann, Neverla, Ammann 2008, s. 22). Z szybszą cyrkulacją obrazów, coraz powszechniejszym do nich dostępem i zwiększoną pojemnością pamięci kontrastuje „drastyczna redukcja długotrwałej stabilności" (Assmann 2004, s. 55).

\section{PERSPEKTYWY BADAWCZE ANALIZY PAMIĘCI WIZUALNEJ}

Pamięć wizualna - spojrzenie w przyszłość: kolektywne posługiwanie się obrazami - jest to wystawa zarówno stała, jak i okresowa. Zbiorowa świadomość historyczna funkcjonuje $\mathrm{w}$ roli kuratora. Ten umieszcza niektóre obrazy w ekspozycji stałej, inne natomiast wiszą tylko przez jakiś czas, a potem znikają $\mathrm{w}$ magazynie. Jeszcze inne są z niego wyciągane i, również okresowo, otrzymują eksponowane miejsce. Wreszcie można zakwestionować w ogóle cały dobór obrazów na takiej wystawie.

Jeszcze nie zostały podjęte prace nad systematyzującym (ewentualnie porównawczym) opisem warunków ramowych genezy indywidualnej historii w danej kulturze pamięci, morfologii i struktury oraz funkcjonalności kolektyw-

${ }^{28}$ Zaznaczenie jest konieczne, gdy dodano lub usunięto osoby i/lub przedmioty; gdy różne elementy obrazu lub obrazy zostały wmontowane, co stworzyło nowe zdjęcie; gdy wprowadzono zmiany w skali i barwach związane z treścią (zob. Büllesbach 2008, s. 114). Jednak tylko ok. 20\% publikacji popiera memorandum. 
nego operowania obrazami w poszczególnych wspólnotach pamięci, podobnie jak nie opracowano narzędzi ich analizy ${ }^{29}$. Należałoby również poddać analizie zmienne wpływy, migrację zdjęć i sposób ich włączenia w kolektywne operowanie obrazami czy też kariery global icons (Haustein 2008), uwzględniając przy tym warunki techniczne, polityczne i kulturowe produkcji zdjęć oraz ich recepcję (konteksty), wizualne przyzwyczajenia (historyczne) producentów i odbiorców, tradycje ikonograficzne i regulacje ekonomicznych procesów ich użycia przez agencje fotograficzne i wydawnictwa. Istnieje bowiem niebezpieczeństwo jednostronnej perspektywy i interpretacji. Analityczne uprzywilejowanie obrazu na przykład grozi zaplątaniem się w sidła immanencji. Analityczne uprzywilejowanie odbiorcy i jego potrzeb degraduje obraz do zwykłej masy dyskursywnej lub powierzchni projekcyjnej, którym nie przyznaje się żadnego własnego ikonicznego znaczenia. Przy takim podejściu nie dałoby się na przykład wyjaśnić oddziaływania obrazów propagandowych niezależnie od kontekstu recepcji. $Z$ kolei analityczne uprzywilejowanie procesów dystrybucji i będących u ich podłoża struktur grozi utratą z pola widzenia specyficznych cech ikonicznych obrazu. Podstawowe wyzwanie dla historiografii polega jednak na tym, żeby odważyć się na wyjście $z$ własnej estetycznej niedojrzałości. A to znaczy przede wszystkim: nauczyć się patrzeć!

\section{BIBLIOGRAFIA}

Amelunxen Hubertus von, Iglhaut Stefan, Rötzer Florian, 1995, Fotografie nach der Fotografie, Dresden - Basel.

Assmann Aleida, 1999, Erinnerungsräume. Formen und Wandlungen des kulturellen Gedächtnisses, München.

Assmann Aleida, 2004, Zur Mediengeschichte des kulturellen Gedächtnisses, w: Astrid Erll, Ansgar Nünning (red.), Medien des kollektiven Gedächtnisses. Konstruktivität, Historizität, Kulturspezifität, Berlin-New York.

Assmann Jan, 2000, Das kulturelle Gedächtnis. Erinnerung und politische Identität in frühen Hochkulturen, München.

Barthes Roland, 2008, Światło obrazu. Uwagi o fotografii, tłum. Jacek Trznadel, Aletheia, Warszawa.

Bergmann Klaus, Schneider Gerhard, 1999, Das Bild, w: Hans-Jürgen Pandel, Gerhard Schneider (red.), Handbuch Medien im Geschichtsunterricht, Schwalbach am Taunus.

Braschler Mathias, 2007, Fischer Monika, About Americans, Heidelberg.

Bredekamp Horst, 2004, Bildakte als Zeugnis und Urteil, w: Monika Flacke (red.), Mythen der Nationen. 1945 - Arena der Erinnerungen, t. 1, Berlin.

Bredekamp Horst, 2010, Theorie des Bildaktes, Berlin.

${ }^{29}$ Wydane przez Gerharda Paula tomy Das Jahrhundert der Bilder. 1900 bis 1949 /1949 bis heute (2008 i 2009) oferują niezwykle szeroką panoramę i ujawniają różnorodność naukowego podejścia. Nie mają jednak na celu systematyzacji. O części kultury wizualnej por. Knoch 2001; raczej deskryptywnie: Hartewig 2010. 
Brink Cornelia, 1998, Ikonen der Vernichtung. Öffentlicher Gebrauch von Fotografien aus nationalsozialistischen Konzentrationslagern nach 1945, Berlin.

Bruder Johannes, 2010, Die Kultur der Komputation, „Kunsttexte”, nr 1.

Büllesbach Alfred, 2008, Digitale Bildmanipulation und Ethik. Aktuelle Tendenzen im Fotojournalismus, w: Elke Grittmann, Irene Neverla, Ilona Ammann (red.), Global, lokal, digital - Fotojournalismus heute, Köln.

Burda Herbert (red.), 2010, In medias res. Zehn Kapitel zum Iconic Turn, München.

Burke Peter, 2001, Eyewitnessing: The Uses of Images as Historical Evidence, Ithaca, NY.

Crivellari Fabio, Sandl Markus, 2003, Die Medialität der Geschichte: Forschungsstand und Perspektiven einer interdisziplinären Zusammenarbeit von Geschichts- und Medienwissenschaften, „Historische Zeitschrift” 277.

Danker Uwe, Schwabe Astrid (red.), 2008, Historisches Lernen im Internet. Geschichtsdidaktik und Neue Medien, Schwalbach am Taunus.

Derrida Jacques, 1988, Die Tode des Roland Barthes, w: Hans-Horst Henschen (red.), Roland Barthes, München.

Dotzler Bernhard J. (red.), 2010, Bild/Kritik, Berlin.

Droysen Johann Gustav, 1977 [1882], Historik. Historische-kritische Ausgabe, Stuttgart.

Dubois Philipe, 1998, Der fotografische Akt. Versuch über ein theoretisches Dispositiv, Amsterdam-Dresden.

Fahlenbrach Kathrin, Viehoff Reinhold, 2005, Medienikonen des Krieges. Die symbolische Entthronung Saddams als Versuch strategischer Ikonisierung, w: Thomas Knieper, Marion G. Müller (red.), War Visions. Bildkommunikation und Krieg, Köln.

Flusser Vilém, 1997, Für eine Philosophie der Fotografie, Göttingen.

Geimer Peter, 2009, Theorien der Fotografie zur Einführung, Hamburg.

Goertz Hans-Jürgen, 1995, Umgang mit Geschichte, Hamburg.

Goertz Hans-Jürgen, 2001, Unsichere Geschichte, Stuttgart.

Gerhard Paul, 2005, Der Bilderkrieg. Inszenierungen. Bilder und Perspektiven der „Operation Irakische Freiheit", Göttingen.

Gerhard Paul, 2008 i 2009, Das Jahrhundert der Bilder, t. 1: 1900 bis 1949, t. 2: 1949 bis heute, Göttingen.

Gerhard Paul, 2011, Die (Zeit-)Geschichte und die Bilder, w: Saskia Handro, Bernd Schönemann (red.), Visualität und Geschichte, Berlin.

Grittmann Elke, 2007, Das politische Bild. Fotojournalismus in Theorie und Empirie, Köln.

Grittmann Elke, Ammann Ilona, 2008, Ikonen der Kriegs- und Krisenfotografie, w: Elke Grittmann, Irene Neverla, Ilona Ammann (red.), Global, lokal, digital - Fotojournalismus heute, Köln.

Grittmann Elke, Neverla Irene, Ammann Ilona, 2008, Global, lokal, digital — Strukturen und Tendenzen im Fotojournalismus, w: Elke Grittmann, Irene Neverla, Ilona Ammann (red.), Global, lokal, digital - Fotojournalismus heute, Köln.

Gudehus Christian, 2010, Eichenberg Ariane, Welzer Harald (red.), Gedächtnis und Erinnerung. Ein interdisziplinäres Handbuch, Stuttgart-Weimar.

Hagen Wolfgang, 2002, Die Entropie der Fotografie. Skizzen zu einer Genealogie der digital-elektronischen Bildaufzeichnung, w: Herta Wolf (red.), Fotokritik am Ende des fotografischen Zeitalters, t. 1: Paradigma Fotografie, Frankfurt am Main.

Hamann Christoph, 2007, Visual History und Geschichtsdidaktik. Bildkompetenz in der historisch-politischen Bildung, Herzbolzheim. 
INDEKS, IKONA I SYMBOL. O STOSUNKU FOTOGRAFII, HISTORII (CZASU) I PAMIĘCI 125

Hamann Christoph, 2011, Zum Eigensinn der Fotografie, w: Saskia Handro, Bernd Schönemann (red.), Visualität und Geschichte, Berlin.

Handro Saskia, Schönemann Bernd (red.), 2011, Visualität und Geschichte, Berlin.

Hariman Robert, Lucaitis John Louis, 2007, No captain needed. Iconic Photographs, Public Culture and Liberal Democracy, Chicago-London.

Hartewig Karin, 2002, Fotografien, w: Michael Maurer, Aufriß der historischen Wissenschaften, t. 4: Quellen, Stuttgart.

Hartewig Karin, 2010, Wir sind im Bilde. Eine Geschichte der Deutschen in Fotos vom Kriegsende bis zur Entspannungspolitik, Leipzig.

Haustein Lydia, 2008, Global Irons. Globale Bildinszenierung und kulturelle Identität, Göttingen.

Heßler Martina, 2005, Bilder zwischen Kunst und Wissenschaft: Neue Herausforderungen für die Wissenschaft, „Geschichte und Gesellschaft”, nr 2.

Hellmold Martin, 1999, Warum gerade diese Bilder? Überlegungen zur Ästhetik und Funktion der historischen Referenzbilder moderner Kriege, w: Thomas F.Schneider (red.), Kriegserlebnis und Legendenbildung. Das Bild des modernen Krieges in Literatur, Theater, Photographie und Film, t. 1: Vor dem Ersten Weltkrieg/Der Erste Weltkrieg, Osnabrück.

Holzwarth Werner, Gamper Peter (red.), 1998, Kollektive Bilder. Die Bilder im Kopf der DDR-Bürger, Weimar.

Jäger Jens, 2009, Fotografie und Geschichte, Frankfurt-New York.

Kemp Wolfgang, 2006, Foto-Essays zur Geschichte und Theorie der Fotografie, München.

Kemp Wolfgang, Amelunxen Hubertus von (red.), 2000, Theorie der Fotografie, 4. t., München.

Kerbs Diethart, 1989, Methoden und Probleme der Bildquellenforschung, w: Neue Gesellschaft für Bildende Kunst (wyd.), Revolution und Fotografie. Berlin 1918/19, Berlin.

Kittler Friedrich, 2002, Computergrafik. Eine halbtechnische Einführung, w: Herta Wolf, Fotokritik am Ende des fotografischen Zeitalters, t. 1: Paradigma Fotografie, Frankfurt am Main.

Knoch Habbo, 2001, Die Tat als Bild. Fotografien des Holocaust in der deutschen Erinnerungskultur, Hamburg.

Krauss Rosalind, 2002, Anmerkungen zum Index, w: Herta Wolf, Fotokritik am Ende des fotografischen Zeitalters, t. 1: Paradigma Fotografie, Frankfurt am Main.

Krüger Klaus, 1997, Geschichtlichkeit und Autonomie: Die Ästhetik des Bildes als Gegenstand historischer Erfahrung, w: Otto Gerhard Oexle (red.), Der Blick auf die Bilder. Kunstgeschichte und Geschichte im Gespräch, Göttingen.

Lethen Helmuth, 2004, Nichts dahinter. Auf der Suche nach dem Ereignis unter der Oberfläche der Medien, w: Malte Hagener, Johann N. Schmidt, Michael Wedel (red.), Die Spur durch den Spiegel. Der Film in der Kultur der Moderne, Berlin.

Löffler Petra, 2010, Licht, Spur, Messung, w: Bernhard J. Dotzler (red.), Bild/Kritik, Berlin.

Lunenfeld Peter, 2002, Digitale Fotografie. Das dubitative Bild, w: Herta Wolf, Fotokritik am Ende des fotografischen Zeitalters, t. 1: Paradigma Fotografie, Frankfurt am Main.

Maar Christa, Burda Herbert (red.), 2004, Iconic Turn. Die neue Macht der Bilder, Köln.

Maar Christa, Burda Herbert (red.), 2006, Iconic Worlds. Neue Bildwelten und Wissensräume, Köln.

Mitchell William T., 1992, The Reconfigured Eye: Visual Truth in the Post-Photographic Era, Cambridge-London. 
Münkler Herfried, 2006, Der Wandel des Krieges. Von der Symmetrie zur Asymmetrie, Weilerswist.

Pandel Hans-Jürgen, 2008, Bildinterpretation. Die Bildquelle im Geschichtsunterricht. Bildinterpretation I, Schwalbach am Taunus.

Reichhardt Rolf, 2006, Bild- und Mediengeschichte, w: Joachim Eibach, Günther Lottes (red.), Kompass der Geschichtswissenschaft, Göttingen.

Ritchin Fred, 1990, Photojournalism in the Age of Computers, w: Carol Squiers (red.), The Critical Image. Essays on Contemporary Photography, Seattle-Washington.

Ritchin Fred, 1999, In Our Own Image, New York.

Rötzer Florian, 1995, Betrifft: Fotografie, w: Hubertus von Amelunxen, Stefan Iglhaut, Florian Rötzer, Fotografie nach der Fotografie, Dresden-Basel.

Rötzer Florian, 2006, Die Wahrheit der digitalen Bilder, „Telepolis”, 7 sierpnia. (http://www.heise.de/tp/artikel/23/23280/1.html [21.04.2011]).

Rusch Gebhard, 1997, Konstruktivismus und Traditionen der Historik, „Österreichische Zeitschrift für Geschichtswissenschaften" 8, nr 1.

Rüsen Jörn, 1994, Was ist Geschichtskultur? Überlegungen zu einer neuen Art, über Geschichte nachzudenken, w: Klaus Füßman, Heinrich Theodor Grütter, Jörn Rüsen (red.), Historische Faszination - Geschichtskultur heute, Köln-Weimar-Wien.

Sachs-Hombach Klaus (red.), 2005a, Bildwissenschaft. Disziplinen, Themen, Methoden, Frankfurt am Main.

Sachsse Rolf, 2003, Fotografie. Vom technischen Bildmittel zur Krise der Repräsentation, Köln.

Sauer Michael, 2000, Bilder im Geschichtsunterricht, Seelze-Velber.

Schierl Thomas, 2005b, Werbungsforschung, w: Klaus Sachs-Hombach (red.), Bildwissenschaft. Disziplinen, Themen, Methoden, Frankfurt am Main.

Schirner Michael, 1987, Bilder im Kopf oder die Magie des Gedruckten, eine Ausstellung vom Stern, Die SternBibliothek, Hamburg.

Schirner Michael, 2007, Bilder im Kopf der Chinesen, w: NRW-Forum für Kultur und Wirtschaft (wyd.), Bilder im Kopf, Düsseldorf.

Schirner Michael, 2010, Bye, bye, Markus Peichl (red.), Hamburg. ???

Schneider Gerhard (red.), 2002, Die visuelle Dimension des Historischen, Schwalbach am Taunus.

Schröter Jens, 2003, Virtuelle Kamera. Zum Fortbestand fotografischer Medien in computergenerierten Bildern, „Fotogeschichte”, t. 23, z. 88.

Schröter Jens, 2004, Das Ende der Welt. Analoge vs. Digitale Bilder - mehr oder weniger „Realität”?, w: Jens Schröter, Alexander Böhnke (red.), Analog/Digital. Opposition oder Kontinuum. Zur Theorie und Geschichte einer Unterscheidung, Medienumbrüche, Bielefeld.

Sontag Susan, 2009, O fotografii, tłum. Sławomir Magala, Karakter, Kraków.

Sontag Susan, 2010, Widok cudzego cierpienia, tłum. , Karakter, Kraków.

Starl Timm, 2002, Dokumentarische Fotografie, w: Hubertus Butin (red.), Begriffslexikon der zeitgenössischen Kunst, Köln.

Thiele Johannes (red.), 2005, Die Bilder der Deutschen. Was uns verbindet, was uns bewegt, München.

Ullrich Wolfgang, 1997, Digitaler Nominalismus. Zu Stand der Computerfotografie, „Fotogeschichte", t. 17, z. 64 .

Warner Marien Mary, 2002, Photography: A Cultural History, London.

Wells Liz (red.), 2009 [1996], Photography: A Critical Introduction, New York. 
INDEKS, IKONA I SYMBOL. O STOSUNKU FOTOGRAFII, HISTORII (CZASU) I PAMIĘCI 127

Welzer Harald (red.), 2001, Das soziale Gedächtnis. Geschichte, Erinnerung, Tradierung, Hamburg.

Wirsching Andreas, 2006, Neueste Zeit, München.

Wittmann Mirjam, 2010, Die Logik des Wetterhahns. Kurzer Kommentar zur Debatte um fotografische Indexikalität, „Kunsttexte.de”, nr 1.

Wolf Herta (red.), 2002, Fotokritik am Ende des fotografischen Zeitalters, t. 1: Paradigma Fotografie, Frankfurt am Main.

Wolf Herta (red.), 2003, Fotokritik am Ende des fotografischen Zeitalters, t. 2: Diskurse der Fotografie, Frankfurt am Main.

Wyss Beat, 2000, Das indexikalische Bild. Hors-texte, „Fotogeschichte”, z. 76.

Tłumaczyła Elżbieta Kaźmierska

INDEX, ICON AND SYMBOL:

ON THE RELATIONSHIP OF PHOTOGRAPHY, HISTORY (TIME) AND MEMORY

Summary

The Author starts with a thesis that photography and modern historiography developed at the same time, and then tries to look for relationships between the two. He starts from analyzing a specificity of a photograph which — as a medium — not only represents the past, but can be an energizing impulse both in the presence and the future. By referring to the semiotic classification of Charles Sanders Peirce, the Author describes the importance of a photograph to historical research as an index, an icon and a symbol. This helps understand the way of using a collective resource of photographs and to define a status of digital photographs as a source. Finally, the Author tries to show the perspectives of visual history analysis and the role which might be played by images when forming and changing memory communities in the era of globalization and diversification.

\section{Key words/słowa kluczowe}

photography / fotografia; history / historia; medium / medium; image /obraz; memory community / wspólnota pamięci 